\title{
Temporal and spatial variations of the active layer along the Qinghai-Tibet Highway in a permafrost region
}

\author{
LI Ren ${ }^{1,2,3}$, ZHAO Lin ${ }^{1,2,3^{*}}$, DING YongJian ${ }^{2,3}$, WU TongHua ${ }^{1,2,3}$, XIAO Yao $^{1,2,3}$, DU ErJi ${ }^{1,2,3}$, \\ LIU GuangYue ${ }^{1,2,3} \&$ QIAO YongPing ${ }^{1,2,3}$
}

${ }^{1}$ Research Station on Cryosphere of Qinghai-Xizang (Tibet) Plateau, Lanzhou 730000, China;
${ }^{2}$ State Key Laboratory on Cryospheric Sciences, Lanzhou 730000, China;
${ }^{3}$ Cold and Arid Regions Environmental and Engineering Research Institute, Chinese Academy of Sciences, Lanzhou 730000, China

Received November 25, 2011; accepted April 26, 2012; published online July 26, 2012

\begin{abstract}
Using monitored active layer thickness (ALT) and environmental variables of 10 observation fields along the Qinghai-Tibet Highway in permafrost region of the Qinghai-Tibetan Plateau (QTP), a model for ALT estimation was developed. The temporal and spatial characteristics of the ALT were also analyzed. The results showed that in the past 30 years ALT in the study region increased at a rate of $1.33 \mathrm{~cm} \mathrm{a}^{-1}$. Temperatures at the upper limit of permafrost and at $50 \mathrm{~cm}$ depth, along with soil cumulative temperature at $5 \mathrm{~cm}$ depth also exhibited a rising trend. Soil heat flux increased at a rate of $0.1 \mathrm{~W} \mathrm{~m}^{-2} \mathrm{a}^{-1}$. All the above changes demonstrated that the degradation of permafrost happened in the study region on the QTP. The initial thawing date of active layer was advanced, while the initial freezing date was delayed. The number of thawing days increased to a rate of $1.18 \mathrm{~d} \mathrm{a}^{-1}$. The variations of active layer were closely related to the permafrost type, altitude, underlying surface type and soil composition. The variations were more evident in cold permafrost region than in warm permafrost region, in high-altitude region than in low-altitude region, in alpine meadow region than in alpine steppe region; and in fine-grained soil region than in coarse-grained soil region.
\end{abstract}

Qinghai-Tibetan Plateau, active layer, thermodynamic processes, accumulated temperature, number of thawing days, freeze and thaw thickness

Citation: Li R, Zhao L, Ding Y J, et al. Temporal and spatial variations of the active layer along the Qinghai-Tibet Highway in a permafrost region. Chin Sci Bull, 2012, 57: 4609-4616, doi: 10.1007/s11434-012-5323-8

As one of the most active regions with respect to global climate change, the Qinghai-Tibetan Plateau (QTP) is a powerful "engine" that can start or regulate certain types of climate change [1,2]. The QTP is a giant tectonic geomorphic unit, at the highest altitude on Earth, and has a unique natural environment that follows a special differentiation law. The plateau has unique subsurface hydrothermal regimes that are controlled by regional atmospheric circulation and the plateau's topographic patterns. Studies show that these subsurface conditions can also govern regional atmospheric circulation and synoptic weather [3,4]. The storage and release of heat in the soil of the QTP can trigger changes in weather, such as altering the trough-ridge alloca-

*Corresponding author (email: linzhao@1zb.ac.cn) tion of the East Asian weather system [5-8].

Permafrost occupies two-thirds of the total area of the QTP. It is an important component of the plateau's soil, and of the cryosphere, and an indicator of climate change [9]. As a "buffer layer" between permafrost and the atmosphere, the active layer is sensitive to climate change, and responds quickly to temperature changes [8]. The active layer controls energy and water exchange between the soil and the atmosphere, which results from changes in soil water content and temperature. To some degree, it reflects the thermal condition of the underlying surface, and therefore it can be used as a thermal indicator of the plateau surface [10]. Previous studies show that the hydrothermal variations in the active layer affect the hydrology and ecosystem in the region [11-15]. Studies of the active layer and permafrost on 
the QTP have received much recent attention [16-20]. Recent work in the area has shown that, due to global climate warming, the permafrost on the QTP has degraded remarkably, including a rise in permafrost temperature, an increase in the thickness of the active layer, and a decrease in permafrost area [21-24]. This degradation of permafrost may alter the groundwater table, resulting in more arid soil, and exacerbating desertification $[21,25,26]$. By analyzing the thermodynamic processes of the QTP active layer, Ding et al. [13] concluded that the active layer thickness (ALT) was closely related to the soil cumulative temperature at $4 \mathrm{~cm}$ depth, while Wu et al. $[15,23]$ showed that ALT was closely related to soil temperature at $50 \mathrm{~cm}$ depth.

Most recent work on the QTP focuses on the changes in the ALT of the plateau, but little research has dealt with the regional differentiation of ALT and the changes in the internal thermodynamic characteristics of the plateau. In addition, most observations of the hydrothermal process of the active layer have been of short duration.

Recent studies show that air temperature on the QTP has increased remarkably, with the largest temperature increase in winter [27,28]; twice as high as the rate of rise of the annual mean temperature. However, it is still not clear what the effect of higher winter temperatures might have on ALT. Using active-layer monitoring data recorded at more than ten observation stations at the Chinese Academy of Science's Cryosphere Research Station on the QTP, we measured the variation of ALT at a mean altitude in the study region. Our data, in combination with meteorological data from the study region, allowed us to (1) develop a climatological model of ALT, (2) analyze recent variation in the thermodynamic conditions of the active layer from changes in soil temperature and ALT, and (3) explore the effects of permafrost type, altitude, underlying surface vegetation type, and soil composition on the thickness and temperature of the active layer.

\section{Study region, methods, and data sources}

The ten observation stations in the study region are distrib- uted on both sides of the Qinghai-Tibet Highway from the Kunlun pass (China06, or simply CN06) to Liangdaohe (China04, or CN04), a distance from south to north of 593 $\mathrm{km}$. The study region includes ecosystems such as alpine frost marsh meadow, alpine frost meadow, alpine frost steppe, alpine frost meadow, and alpine frost desert steppe. The altitude ranges from 4400 to $5100 \mathrm{~m}$, with a mean altitude of more than $4700 \mathrm{~m}$ above the sea level (Table 1). Measurements were collected between 2004 and December 2010, and included soil temperature, surface soil heat flux, air temperature, surface temperature, vapor pressure, precipitation, and wind velocity. Meteorological data were collected at the Wudaoliang Meteorological station in the interior of the QTP.

Soil temperatures were monitored using $105 \mathrm{~T}$ thermistor sensors, with an accuracy of $0.1^{\circ} \mathrm{C}$. Soil heat fluxes were measured with a HFPOISC self-calibration. Instruments were attached to a CR1000 data logger (Campbell Company). The time zone was set at Beijing time. Data were collected once every $30 \mathrm{~min}$ or $2 \mathrm{~h}$ (once every $30 \mathrm{~min}$ for QT observation fields; once every $2 \mathrm{~h}$ for $\mathrm{CN}$ observation fields). ALT was determined by measuring the maximum depth of the $0^{\circ} \mathrm{C}$ isotherm, observed from the soil temperature profile.

Mean annual air temperature in the study region is ranges from -7.1 to $-1.8^{\circ} \mathrm{C}$, and mean annual precipitation is 300 to $500 \mathrm{~mm}$, and mainly occurs in May-September, characteristic of a typical plateau sub-frigid semiarid climate. The permafrost temperature measured at $6 \mathrm{~m}$ depth varied between -3.2 and $0.2^{\circ} \mathrm{C}$, and the ALT thickness varied between 105 and $322 \mathrm{~cm}$ [23]. Analytical results of soil samples in the study region show that fine particles smaller than $0.054 \mathrm{~mm}$ in the active-layer soil varied between $4.8 \%$ and $28.2 \%$.

The longest continuous observation sequence of ALT on the QTP is only 12 years, a significant limitation on the study of the response of the active layer to climate change. Standard meteorological stations in the study region provide a long sequence of observation data.

We corrected for the various altitudes of the observation stations by calculating a mean altitude of the study region.

Table 1 Location and underlying surface conditions of active-layer measurements in the study region [23]

\begin{tabular}{|c|c|c|c|c|c|c|c|}
\hline Location & Station number & $\begin{array}{l}\text { Latitude } \\
\left({ }^{\circ} \mathrm{N}\right)\end{array}$ & $\begin{array}{c}\text { Longitude } \\
\left({ }^{\circ} \mathrm{E}\right)\end{array}$ & $\begin{array}{l}\text { Altitude } \\
\text { (m) }\end{array}$ & Underlying surface type & $\begin{array}{c}<0.054 \mathrm{~mm} \text { particle } \\
(\%)\end{array}$ & Period of data collection \\
\hline Kunlun pass & CN06 & 35.62 & 94.07 & 4746 & Alpine frost sparse steppe & 8.8 & 2003-09-2010-12 \\
\hline Suonandajie & $\mathrm{CNO} 2$ & 35.43 & 93.60 & 4488 & Alpine frost steppe & 4.8 & 1999-08-2010-12 \\
\hline Hoh Xil & QT01 & 35.15 & 93.05 & 4734 & Alpine frost meadow & 28.2 & 2003-09-2010-12 \\
\hline Beiluhe 1 & QT02 & 34.82 & 92.92 & 4656 & Alpine frost meadow & 11.4 & 2003-09-2010-12 \\
\hline Beiluhe 2 & QT03 & 34.82 & 92.92 & 4656 & Alpine frost meadow & 17.1 & 2003-09-2010-12 \\
\hline Fenghuoshan & CN01 & 34.73 & 92.90 & 4896 & Alpine frost meadow & 26.9 & $1998-05-2010-12$ \\
\hline Kaixinling & QT05 & 33.95 & 92.40 & 4652 & Alpine frost desert steppe & 7.9 & 2003-09-2010-12 \\
\hline Tongtianhe & QT06 & 33.58 & 92.24 & 4650 & Alpine frost steppe & 10.6 & 2003-09-2010-12 \\
\hline Tanggula & QT04 & 32.97 & 91.02 & 5100 & Degraded alpine frost meadow & 5.8 & $2005-10-2010-12$ \\
\hline Liangdaohe & $\mathrm{CNO} 4$ & 31.82 & 91.73 & 4808 & Alpine frost marsh meadow & 18.6 & $1999-08-2010-12$ \\
\hline
\end{tabular}




$$
\mathrm{ALT}_{i}^{*}=\frac{\bar{H}}{H_{i}} \times \mathrm{ALT}_{i},
$$

where $\mathrm{ALT}_{i}^{*}$ is the corrected ALT of different stations, and $\bar{H}$ is the mean altitude of the stations in the study region. $H_{i}$ and $\mathrm{ALT}_{i}$ are altitude and ALT of the stations, respectively. Using the altitude correction, ALT data from the different observation stations could be compared. From 2004 to 2010, the mean ALT in the study region was 27.3 $\mathrm{cm}$ thicker than the mean value for $\mathrm{CN} 02, \mathrm{CN} 01$, and CN04 during the same time (between 24 and $36 \mathrm{~cm}$ ). Prior to 2004, data are only available for $\mathrm{CN} 02, \mathrm{CN} 01$, and CN04; therefore, the mean ALT on the QTP in 1998-2003 must be approximated using the mean values of $\mathrm{CN} 02, \mathrm{CN} 01$, and CN04 plus $27.3 \mathrm{~cm}$.

We analyzed the relationship between meteorological variables and ALT using a statistical method. Using a multiple regression method, we selected the variables of summer air temperature $\left(T_{\mathrm{a}},{ }^{\circ} \mathrm{C}\right)$, soil negative cumulative temperature $\left(\mathrm{CTN},{ }^{\circ} \mathrm{C} \mathrm{d}\right.$ and positive cumulative temperature (CTP, ${ }^{\circ} \mathrm{C} \mathrm{d}$ ) [29] at $5 \mathrm{~cm}$ depth in a complete freeze-thaw cycle, together with the data from 1998-2009, the following regression model was constructed:

$$
\mathrm{ALT}=a \cdot T a+b \cdot \mathrm{CTN}+c \cdot \mathrm{CTP}+d,
$$

where $a, b, c$, and $d$ are regression coefficients (Table 2). The partial correlation coefficients of various factors and ALT were larger than 0.980 . The multiple correlation coefficient of the model was 0.866. An F test for the model at 0.01 confidence interval was passed. The standard deviation of the model was $6.4 \mathrm{~cm}$. Mean absolute error was $4.8 \mathrm{~cm}$, and mean relative error was $2.4 \%$. Extrapolation test (2010 data were not used in the model construction) results showed that the absolute error of the regression model was $10.0 \mathrm{~cm}$ and its relative error was $4.3 \%$. It can be seen that the calculation error of the regression model is relatively small, and the independent variables were easily obtained, and thus the model can be used to estimate the mean ALT in the study region.

The regression analysis showed that as CTN and CTP increased $100{ }^{\circ} \mathrm{C} \mathrm{d}$, the contribution of CTN to increased ALT is $7 \mathrm{~cm}$, while the contribution of CTP is $4 \mathrm{~cm}$. The contribution of CNT to ALT is $3 \mathrm{~cm}$ larger than that of CTP. In addition, the partial correlation coefficient between CTN and ALT in the regression model reached 0.997, which suggests that its effect on ALT is significant. Furthermore, winter temperature is also an important influencing factor.

\section{Results and analysis}

\subsection{Variations in ALT along the Qinghai-Tibet High- way}

We calculated the mean ALT in the study region between 1981 and 1997 and, combined with the observed data from
1998-2010, we obtained the ALT over 30 years from 1981 to 2010. The results (Figure 1) show that the ALT in the permafrost along the Qinghai-Tibet Highway has exhibited a remarkable increasing trend in the past 30 years. In the 1980s, the mean ALT was $179 \mathrm{~cm}$, and the mean ALT increased by $14 \mathrm{~cm}$ in the 1990s. The ALT in 2001-2010 increased by $19 \mathrm{~cm}$ over that of the 1990s. Over the past 30 years, the ALT, on average, increased by $13.3 \mathrm{~cm}$ per decade. Correspondingly, the mean air temperature in the study region in the $1980 \mathrm{~s}$ was $-5.2^{\circ} \mathrm{C}$. In the $1990 \mathrm{~s}$, it increased by $0.5^{\circ} \mathrm{C}$. In $2001-2010$, mean air temperature increased by $1.1^{\circ} \mathrm{C}$ compared to the $1990 \mathrm{~s}$. On average, air temperature increased by $0.79^{\circ} \mathrm{C}$ every 10 years.

The correlation coefficient between annual mean air temperature and ALT on the QTP reached $0.66(P<0.01)$. Over the past 30 years, the variation of ALT coincided with climate warming on the plateau, with ALT increasing with increasing temperature. We also found that mean air temperature increased most in winter, reaching $1.2^{\circ} \mathrm{C}$ per decade. The correlation coefficient of winter air temperature and ALT reached $0.72(P<0.01)$. When the winter temperature was high, the temperature of the active layer in the corresponding period was also high; and in the subsequent thawing processes, the heat consumed during the rise of the active layer temperature was relatively small. More heat was consumed in the thawing of active layer, and therefore the ALT increased. This shows that ALT is not only related to summer temperatures, but that winter temperatures also have an important contribution to ALT.

\subsection{Regional differences in variation of ALT}

Our study shows that (Figure 2) the mean ALT in permafrost along the Qinghai-Tibet Highway was $218 \mathrm{~cm}$, with a range of 100-320 cm and an overall increasing trend. In the past 13 years, the ALT increased by $46 \mathrm{~cm}$, with a variation rate of $3.6 \mathrm{~cm} \mathrm{a}^{-1}$. This value is smaller than that observed by $\mathrm{Wu}$ et al. [22] $\left(7.5 \mathrm{~cm} \mathrm{a}^{-1}\right)$. The main reason for this difference lies in the fact that the observation sites selected by $\mathrm{Wu}$ et al. [22] were mostly set up for dynamic monitoring of the Qinghai-Tibet Highway/Railway embankment in permafrost.

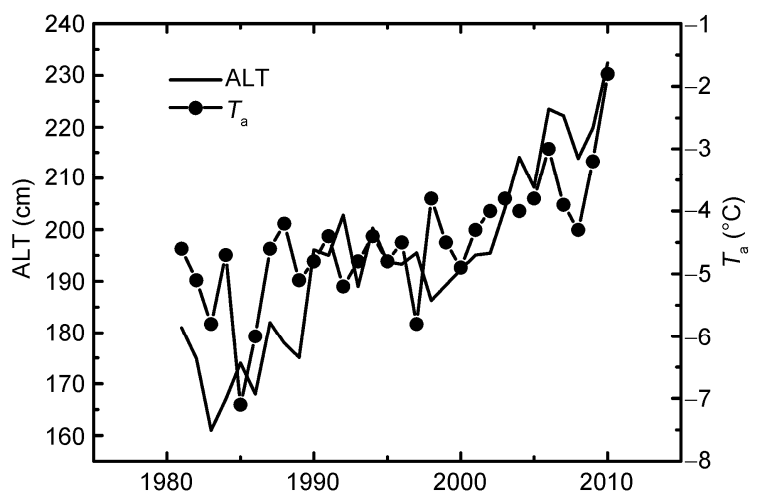

Figure 1 Changes of ALT and $T_{\mathrm{a}}$ in the permafrost zone. 
Table 2 Regression coefficient and correlation coefficient of the model

\begin{tabular}{|c|c|c|c|c|c|c|c|c|}
\hline \multicolumn{4}{|c|}{ Regression coefficient } & \multicolumn{3}{|c|}{ Partial correlation coefficient } & \multirow{2}{*}{$\begin{array}{c}\text { Multiple correlation coefficient } \\
r\end{array}$} & \multirow{2}{*}{$\begin{array}{c}F \text { test value } \\
f\end{array}$} \\
\hline$a$ & $b$ & $c$ & $d$ & $r(\mathrm{Ta})$ & $r(\mathrm{CTN})$ & $r(\mathrm{CTP})$ & & \\
\hline-7.00 & 0.07 & 0.04 & 272.88 & 0.985 & 0.997 & 0.994 & 0.866 & 7.993 \\
\hline
\end{tabular}

Therefore most of them are located within the range of tens of meters on both sides of the highway/railway, where road engineering and human activity disturbance is more frequent, and thus the increase in ALT is larger. However, our observation sites are mostly away from the highway/railway, within a few hundred meters, where human activity disturbance is smaller. In addition, the timeframe of our study may also be a reason for the variation in ALT increase rate. Our observation records up to 2010 show that, in the cold permafrost region (ground temperature at annual variation layer is lower than $\left.-1.5^{\circ} \mathrm{C}[30]\right)$, the increase in ALT varied between 13 and $78 \mathrm{~cm}$; on average it increased by $34 \mathrm{~cm}$. And the linear variation rate of ALT varied between 1.4 and $6.3 \mathrm{~cm} \mathrm{a}^{-1}$, with an average of $3.1 \mathrm{~cm} \mathrm{a}^{-1}$. Compared to the cold permafrost region, the increased ALT in the warm permafrost region (ground temperature at annual variation layer is higher than $-1.5^{\circ} \mathrm{C}$ ) varied between 15 and $35 \mathrm{~cm}$. On average, ALT increased by $22 \mathrm{~cm}$. ALT varied at -0.5 $\mathrm{cm} \mathrm{a}^{-1}$ at QT05, and the variation rate of ALT at the rest of observation sites was between 0.8 and $3.2 \mathrm{~cm} \mathrm{a}^{-1}$, with an average of $2.4 \mathrm{~cm} \mathrm{a}^{-1}$. The results in the warm permafrost region show that the mean variation in ALT in the hinterland of the plateau was $20 \mathrm{~cm}$, while that in the marginal region was larger than $30 \mathrm{~cm}$.

During the study period, air temperature and ALT at various observation sites exhibited the same variation trend; the mean annual air temperature increased $0.13^{\circ} \mathrm{Ca}^{-1}$. Air temperature varied seasonally, and the winter temperature warming rate was the largest, reaching $0.39^{\circ} \mathrm{C} \mathrm{a}^{-1}$, while the summer warming rate was only $0.018^{\circ} \mathrm{C} \mathrm{a}^{-1}$. This further demonstrates that the higher warming rate in winter has an important effect on the variation of ALT.

Additionally, from the comparison of Figure 2 and Table 1 , we can see that the altitude and annual mean air

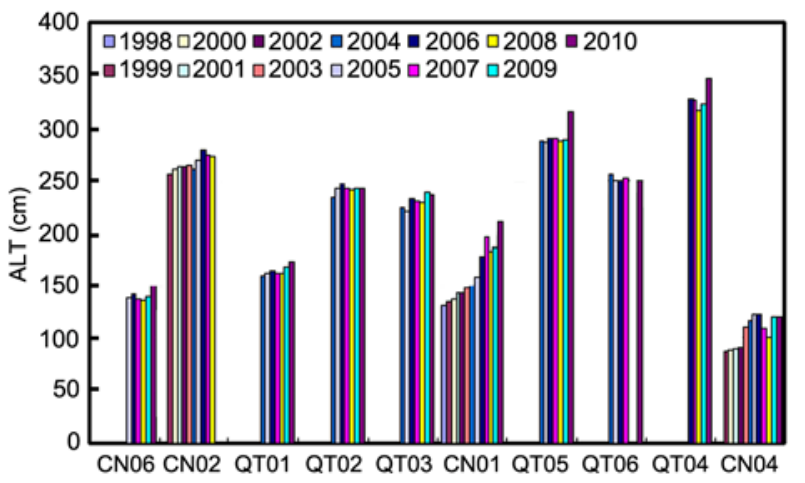

Figure 2 Changes of ALT at different observation stations along the Qinghai-Tibet Highway. temperature at QT05 and QT06 are comparable, but their ALT differs by $40 \mathrm{~cm}$. The distance between QT02 and QT03 is less than $10 \mathrm{~m}$, their altitude and air temperature are the same, but their ALTs differ by $12 \mathrm{~cm}$. Therefore air temperature determines the variation of ALT, although local factors (altitude, precipitation, land cover (vegetation and snow cover), and soil composition at different sites) also have an important effect on ALT.

From the analysis of altitude, permafrost type, and underlying surface type of the observation sites in relation to the variation of ALT, we found that ALT decreased, and its variation amplitude increased, with increasing altitude. Each $100 \mathrm{~m}$ increase in altitude led to a $6.7 \mathrm{~cm}$ increase in ALT. At the sites with altitudes above $4700 \mathrm{~m}$, the mean variation of ALT was nearly $34 \mathrm{~cm}$, with a mean variation rate of 3.1 $\mathrm{cm} \mathrm{a}^{-1}$. At the sites with altitudes below $4700 \mathrm{~m}$, the mean variation of ALT was approximately $18 \mathrm{~cm}$, with a mean variation rate of $1.6 \mathrm{~cm} \mathrm{a}^{-1}$. Observation sites of alpine meadow type showed a mean variation of ALT of nearly 30 $\mathrm{cm}$, with a mean variation rate of $2.7 \mathrm{~cm} \mathrm{a}^{-1}$. Sites of alpine steppe type had a mean ALT variation of $20 \mathrm{~cm}$, with a mean variation rate of $1.8 \mathrm{~cm} \mathrm{a}^{-1}$.

Comparative analyses at sites in cold permafrost showed that ALT at CN06 fluctuated between 137 and $150 \mathrm{~cm}$, with a minimum thickness occurring in $2008(137 \mathrm{~cm})$, and the maximum value in 2010. The variation rate of ALT at CN06 was $1.4 \mathrm{~cm} \mathrm{a}^{-1}$. ALT at QT01 fluctuated between 160 and $173 \mathrm{~cm}$; the minimum value occurred in 2004, and the maximum value in 2010. The variation rate of ALT at QT01 was $1.7 \mathrm{~cm} \mathrm{a}^{-1}$. ALT at CN01 (over a longer observation period) fluctuated between 132 and $210 \mathrm{~cm}$, with the minimum value occurring in 1998, and the maximum value in 2010 . The variation rate of $6.3 \mathrm{~cm} \mathrm{a}^{-1}$ was the largest variation rate of ALT among the 10 observation sites in the study region. And it was close to the value (about $6.0 \mathrm{~cm} \mathrm{a}^{-1}$ ) observed by $\mathrm{Wu}$ and Zhang [22] in a nearby natural observation site.

Comparing ALT at various observation sites (Figure 2) and the underlying soil type and fine particle composition listed in Table 1, we found that ALT at sites in alpine marsh meadows was relatively thin, ALT increased in alpine meadows, and was thickest in alpine steppes. The main reason for this is that as the subsurface transforms from alpine swamp meadow to alpine meadow, alpine steppe, and alpine desert, the vegetation cover and soil moisture content in the active layer gradually decreases; these two factors lower soil temperature in the warm season [30]. Therefore, the ALT of various subsurface types varied greatly. We found that there is a negative correlation between finegrained soil component and ALT, with a correlation coeffi- 
cient of -0.67 . ALT decreases with an increase in fine-grained soil component content. The main reason for this is that fine-grained soil has a better water-holding capacity. Under the same soil moisture conditions, the higher the fine-grained soil component content, the more water will be stored in the soil. Because water evaporation consumes heat, the heat needed for a rise in soil temperature decreases, leading to a decrease of soil temperature, and therefore a thinner ALT.

\subsection{Temperature variation in the active layer and its regional differences}

The temperature at the upper-limit of permafrost (TTOP) is an important indicator of the thermal regime of the active layer. In this study, the temperature measured at the mean depth of the upper limit of permafrost was selected as the TTOP. TTOP and ALT vary consistently. TTOP at $10 \mathrm{ob}-$ servation stations along the Qinghai-Tibet Highway exhibited an increasing trend (Figure 3 ). TTOP ranged from 0.1 to $1.6^{\circ} \mathrm{C}$ across sites, with a mean of $0.7^{\circ} \mathrm{C}$. The mean variation of TTOP in the study region was $0.013^{\circ} \mathrm{C} \mathrm{a}^{-1}$, fluctuating between -0.044 and $0.098^{\circ} \mathrm{C} \mathrm{a}^{-1}$, with a value of $0.032^{\circ} \mathrm{C} \mathrm{a}^{-1}$ in the cold permafrost region and $0.020^{\circ} \mathrm{C} \mathrm{a}^{-1}$ in the warm permafrost region. At sites with altitudes above $4700 \mathrm{~m}$, the mean variation of TTOP was 0.034 and $0.029^{\circ} \mathrm{C} \mathrm{a}^{-1}$ for those with altitudes below $4700 \mathrm{~m}$.

Mean ground temperature in the cold permafrost region rose more than in the warm permafrost region [21,22]. The same result was observed in the Urengoy region in Russia [31], where the warming rate in cold permafrost regions reached $0.045^{\circ} \mathrm{C} \mathrm{a}^{-1}$, but only $0.030^{\circ} \mathrm{C} \mathrm{a}^{-1}$ in warm permafrost regions. A possible reason for this may be that the heat consumption for phase transformation in the cold permafrost region is smaller.

Surface vegetation also has considerable influence on TTOP. Different vegetation types resulted in different TTOP warming rates. The TTOP variation rate was $0.041^{\circ} \mathrm{C}$ $\mathrm{a}^{-1}$ in alpine meadows and $0.009^{\circ} \mathrm{C} \mathrm{a}^{-1}$ for alpine steppes.
The difference in soil moisture content below the various vegetation types is the main factor leading to different warming rates. In alpine meadows, the soil moisture content is relatively high, thus the soil thermal conductivity is large, and the change in soil temperature downward is rapid, so the temperature rise in the lower soil layer is also rapid. Furthermore, because the surface humidity in the alpine meadow sites is high, its surface color is dark and albedo is low. Under the same sunshine condition, its surface can obtain more solar energy to heat the lower soil layer. Therefore, the combined effects of larger thermal conductivity and smaller surface albedo increase the variation rate of TTOP. In addition, soil structure also has a large influence on TTOP. The TTOP decreased with increasing fine-grained soil component content, with a correlation coefficient of -0.67 . In our study region, there is a positive correlation between average TTOP and ALT, with a correlation coefficient of 0.91, and a confidence interval of $\alpha=0.001$.

The characteristics of temperature variation at $50 \mathrm{~cm}$ depth in active layer soil (GT50) are similar to TTOP variation. The GT50 warming rate in the cold permafrost region and high-altitude regions was large $\left(0.105\right.$ and $0.086^{\circ} \mathrm{C} \mathrm{a}^{-1}$, respectively), while that in the warm permafrost region and low-altitude regions was small $\left(0.075\right.$ and $0.078^{\circ} \mathrm{C} \mathrm{a}^{-1}$, respectively). As the underlying surface type transitioned from alpine meadow to alpine steppe, GT50 warming rate decreased. For the alpine meadow type, GT50 warming rate was $0.098^{\circ} \mathrm{C} \mathrm{a}^{-1}$, while for the alpine steppe type, the GT50 warming rate was $0.075^{\circ} \mathrm{C} \mathrm{a}^{-1}$. Statistical analysis showed that there was a better positive correlation between GT50 and ALT, with a correlation coefficient of 0.61 .

Annual soil cumulative temperature (CT) in the shallow layer of the active layer is an important index of soil thermal regime. In our study region, at CN02 and seven other sites, daily mean CT at $5 \mathrm{~cm}$ depth showed an increasing trend. However, the increasing trend in CT in different regions was not the same. In the cold permafrost region, the mean variation of $\mathrm{CT}$ was $595.0^{\circ} \mathrm{C} \mathrm{d}$, with a variation rate of $77.46^{\circ} \mathrm{C} \mathrm{d} \mathrm{a}^{-1}$. In the warm permafrost region, the mean

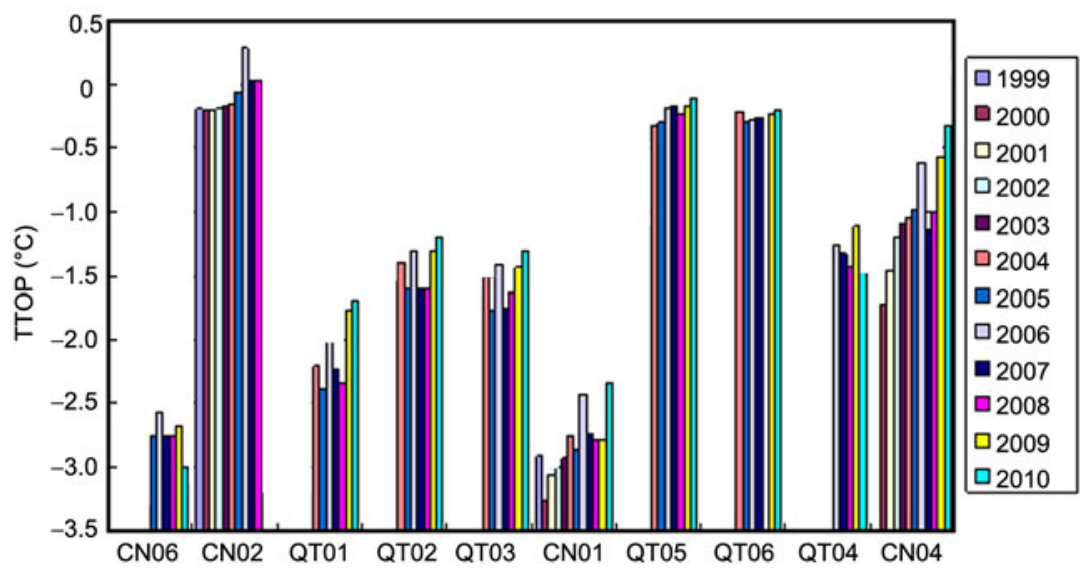

Figure 3 Variations of TTOP at different observation fields. 
variation of $\mathrm{CT}$ was $373.0^{\circ} \mathrm{C}$ d, with a variation rate of $33.45^{\circ} \mathrm{C} \mathrm{d} \mathrm{a}^{-1}$. The variation of $\mathrm{CT}$ at the observation site above $4700 \mathrm{~m}$ altitude was $432.4^{\circ} \mathrm{C} \mathrm{d}$, with a variation rate at $43.23^{\circ} \mathrm{C} \mathrm{d} \mathrm{a}^{-1}$; the corresponding values at the observation site below $4700 \mathrm{~m}$ altitude were $381.8^{\circ} \mathrm{C}$ d with a variation rate of $37.63^{\circ} \mathrm{C} \mathrm{d} \mathrm{a}^{-1}$. For the same reasons mentioned above, in the cold permafrost region and the high-altitude observation site, the heat consumption for phase transformation was relatively low compared to the warm permafrost region and the low-altitude site. The amount of heat used to heat the soil was relatively high; therefore the warming rate of the CT in related regions was high. Our analysis of CT data at sites of different underlying surface types found that the variation of $\mathrm{CT}$ of the active layer at alpine meadow sites was $425.5^{\circ} \mathrm{C} \mathrm{d}$. Its variation rate was $44.38^{\circ} \mathrm{C} \mathrm{d} \mathrm{a}^{-1}$. At alpine steppe sites, the corresponding values were 359.5 and $29.90^{\circ} \mathrm{C} \mathrm{d} \mathrm{a}^{-1}$, respectively. The variation rate of $\mathrm{CT}$ at alpine frost meadow sites was larger than that at alpine steppe type sites, which is caused by the difference in soil texture and water content of the underlying surface. Soil particle size at the alpine meadow site is relatively finer than at the alpine steppe site, while the water-holding capacity is better and the surface albedo is relatively lower. The alpine meadow site obtains more solar energy to heat the soil of active layer, and thus the variation rate of CT value is larger. Due to the higher albedo of relative dry surface soil, the alpine steppe site receives relatively less net radiation, and the amount of heat used to heat the lower soil layer is less, which leads to a smaller variation rate of $\mathrm{CT}$ at the alpine steppe site. As a whole, as CT increases, ALT and TTOP exhibit an increasing trend. On average, as CT increases by $100.0^{\circ} \mathrm{C} \mathrm{d}$, ALT will increase $10 \mathrm{~cm}$, and TTOP increases $0.14^{\circ} \mathrm{C}$.

ALT at the various observation sites can be estimated using the following relationship:

$$
\mathrm{ALT}=0.1157 \cdot \mathrm{CT}+243.8 \text {. }
$$

The linear correlation coefficient of ALT and CT in eq. (3) is 0.60. Extrapolation test results (2010 data are not used to construct the model) show that the absolute error of the results obtained with eq. (3) is $20 \mathrm{~cm}$, and the relative error is $10 \%$. However, the equation is not suitable for the estimation ALT of the CNO4 site at the south edge of the permafrost region, nor of the QTO4 high-altitude site.

\subsection{Variations in soil heat flux}

Soil heat flux represents the amount of net surface radiation distributed in soil. It is an important index to characterize the soil thermal regime. Soil heat flux at $5 \mathrm{~cm}$ depth (Gs5) at five observation sites in our study region exhibited an increasing trend (Figure 4). On average, the maximum value of Gs5 occurred in 2010 and the second maximum value occurred in 2006. The mean value of Gs5 across the five observation sites was $2.6 \mathrm{~W} \mathrm{~m}^{-2}$, and varied between 0.5 and $3.7 \mathrm{~W} \mathrm{~m}^{-2}$, with a mean variation rate of $0.1 \mathrm{~W} \mathrm{~m}^{-2} \mathrm{a}^{-1}$.

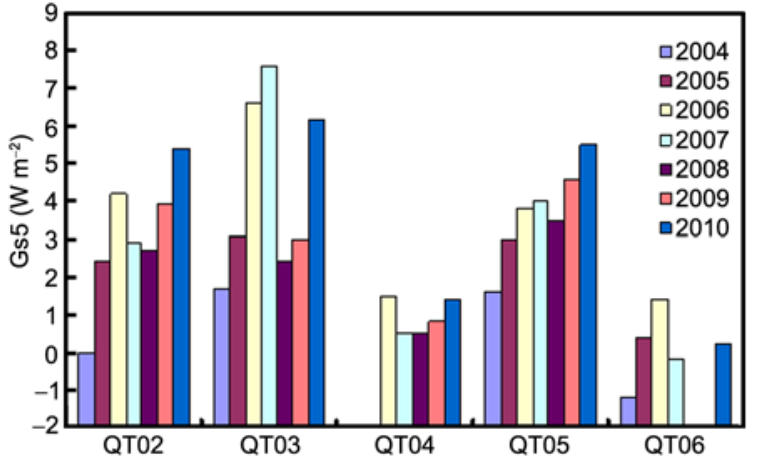

Figure 4 Variation in soil heat flux at $5 \mathrm{~cm}$ depth of the active layer.

The annual mean soil heat flux is greater than $0.0 \mathrm{~W} \mathrm{~m}^{-2}$, which shows that in a year, there is surplus heat amount transferred from the surface to the lower soil layer. The lower soil layer absorbs the heat, and the ALT and TTOP increases. Our analysis showed that, as soil flux increases $1.0 \mathrm{~W} \mathrm{~m}^{-2}$, the ALT increases $24 \mathrm{~cm}$, and TTOP rises $0.3^{\circ} \mathrm{C}$ on average. The correlation coefficients between soil heat flux and ALT and TTOP are 0.93 and 0.84 , respectively.

The variation in soil heat flux is an important cause of soil temperature variation. Soil temperature increases with increasing soil heat flux. This is shown by the increase in soil cumulative temperature and its correlation coefficient of 0.89 .

\subsection{Variations in freeze-thaw time}

The initial freeze date and initial thaw dates at the active layer observation site in our study region exhibited a significant trend. The initial thaw date of several sites was advanced, to varying degrees, while the initial freeze date was delayed, to different degree. As a result, the number of thawing days increased. On average, the initial thaw date of the active layer during 2006-2007 was advanced by $16 \mathrm{~d}$, while the initial freeze date was delayed by 14 days. During this period, the number of thawing days of the active layer increased by $30 \mathrm{~d}$, on average. Compared to 2006-2007, the initial thaw date in 2008 was delayed by $9 \mathrm{~d}$, but the initial freeze date was advanced by $6 \mathrm{~d}$. Lower air temperature across the QTP in 2008 was the main reason for the delay of initial thawing and the advance of initial freezing in that year. As a whole, from the Xidatan at the northern border of the permafrost area to Liangdaohe at the southern border of permafrost, the number of thawing days of the active layer increased variably, and the number of freezing days decreased to different degree. Each year, the number of freezing days decreased by $0.5-2.4 \mathrm{~d}$. The variation rate of the number of freezing days at the southern and northern border of the permafrost region is $-0.81 \mathrm{~d} \mathrm{a}^{-1}$. From Hoh Xil to Tanggula, the variation rate of the number of freezing days varied between -1.3 and $-2.39 \mathrm{~d} \mathrm{a}^{-1}$, and averaged $-1.78 \mathrm{~d}$ $\mathrm{a}^{-1}$. The decrease in freezing days in the permafrost region 
was larger in the hinterland of the QTP than at its southern and northern border. The number of thawing days of the active layer in the study region reached $184 \mathrm{~d}$, on average, with a variation rate of $1.18 \mathrm{~d} \mathrm{a}^{-1}$. The long series of data recorded at Wudaoliang Meteorological Station in the study region revealed that the air temperature across the four seasons during 1981-2010 exhibited a significant increasing trend, with winter temperature warming the largest $\left(0.81^{\circ} \mathrm{C}\right.$ $\left.\mathrm{a}^{-1}\right)$, followed by that in spring $\left(0.59^{\circ} \mathrm{C}^{-1}\right)$; summer and autumn temperature warming rates were approximately $\left(0.47^{\circ} \mathrm{C} \mathrm{a}^{-1}\right)$. As a result, in a freeze-thaw cycle, a great deal of heat was used to heat the soil in the active layer, and soil temperature in the active layer was relatively high; therefore, the initial thawing date of the active layer in spring was advanced more than ever before. But the initial freezing date in autumn was delayed, and the duration of thawing increased. In the past 30 years, the number of thawing days in the Wudaoliang region increased by $7.4 \mathrm{~d}$ per decade.

\section{Conclusions}

In the past 30 years, the mean ALT in the study region increased at a rate of $1.33 \mathrm{~cm} \mathrm{a}^{-1}$. The variation rate of ALT reached $3.1 \mathrm{~cm} \mathrm{a}^{-1}$ in cold permafrost areas and $2.4 \mathrm{~cm} \mathrm{a}^{-1}$ in warm permafrost areas. The variation rate of ALT in the region above $4700 \mathrm{~m}$ altitude reached $3.1 \mathrm{~cm} \mathrm{a}^{-1}$, and in the region below $4700 \mathrm{~m}$ altitude reached $1.6 \mathrm{~cm} \mathrm{a}^{-1}$. ALT variation rate in alpine meadows was $2.7 \mathrm{~cm} \mathrm{a}^{-1}$, and $1.8 \mathrm{~cm} \mathrm{a}^{-1}$ in alpine steppe regions. There was a remarkable negative correlation between the fine-grained soil component and ALT.

As a whole, TTOP in the study region exhibited an increasing trend, with a mean variation rate of $0.031^{\circ} \mathrm{C} \mathrm{a}^{-1}$. The mean variation rate of TTOP in cold permafrost areas was 0.032 and $0.020^{\circ} \mathrm{C} \mathrm{a}^{-1}$ in warm permafrost areas. The mean variation rate of TTOP was $0.034^{\circ} \mathrm{C} \mathrm{a}^{-1}$ in the region above $4700 \mathrm{~m}$ altitude, and $0.029^{\circ} \mathrm{C} \mathrm{a}^{-1}$ in the region below $4700 \mathrm{~m}$ altitude. The TTOP variation rate in alpine meadows was $0.041^{\circ} \mathrm{C} \mathrm{a}^{-1}$, and in alpine steppes it was $0.009^{\circ} \mathrm{C}$ $\mathrm{a}^{-1}$. TTOP decreased with increasing fine-grained soil component content. GT50 and TTOP show a similar variation trend and regional differentiation characteristics.

Cumulative temperature in the study region showed an increasing trend. The variation rate of $\mathrm{CT}$ was $77.46^{\circ} \mathrm{C} \mathrm{d} \mathrm{a}^{-1}$ in cold permafrost area and $33.45^{\circ} \mathrm{C} \mathrm{d} \mathrm{a}^{-1}$ in warm permafrost areas. The variation rate of CT was $43.23^{\circ} \mathrm{C} \mathrm{d} \mathrm{a}^{-1}$ in the region above $4700 \mathrm{~m}$ altitude and $37.63^{\circ} \mathrm{C} \mathrm{d} \mathrm{a}^{-1}$ in the region below $4700 \mathrm{~m}$ altitude. The $\mathrm{CT}$ variation rate reached $44.38^{\circ} \mathrm{C} \mathrm{d} \mathrm{a}^{-1}$ in alpine meadows and $29.90^{\circ} \mathrm{C} \mathrm{d} \mathrm{a}^{-1}$ in alpine steppes. As CT increased, the ALT and TTOP exhibited an increasing trend. Under average conditions, CT increases $100.0^{\circ} \mathrm{C} \mathrm{d}$, ALT increases $10 \mathrm{~cm}$, and TTOP increases $0.14^{\circ} \mathrm{C}$.

Soil heat flux in the study region also shows an increas- ing trend. The $1.0 \mathrm{~W} \mathrm{~m}^{-2}$ increase in soil heat flux leads to a $24 \mathrm{~cm}$ increase in ALT and a $0.3^{\circ} \mathrm{C}$ rise in TTOP. There is a direct correlation between soil heat flux and ALT and TTOP. The initial thawing date of the active layer in the study region is advanced, but the initial freezing date is delayed, and the number of thawing days increased. As a whole, from the Xidatan at the northern border of the permafrost region to Liangdaohe at the southern border of permafrost, the number of thawing days of the active layer increased $0.5-2.4 \mathrm{~d}$.

This work was supported by the National Natural Science Foundation of China (40871037, 40830533 and 40901042), the Hundred Talents Program of the Chinese Academy of Sciences (51Y251571), the National Basic Research Program of China (2007CB411504 and 2007CB411505), Infrastructure Projects from Chinese Ministry Science and Technology (2008FY110200), the State Key Laboratory of Cryospheric Science (SKLCS-ZZ-2010-03), Background of ecological monitoring for the ecological environment protection and construction in Three-Rivers Source Nature Resource Protection Areas-Permafrost monitoring and assessment project, and the Cryosphere Research Station on the Qinghai-Xizang Plateau, Chinese Academic Sciences. The anonymous reviewers for their constructive comments and suggestions are highly acknowledged. The authors wish to express their appreciation to Professor Li Shuxun for his helpful advice that improved the manuscript. The authors also sincerely thank Professor Zhang Tingjun, Professor Yi Shuhua and Doctor Chen Hao for their help in English language. And the authors sincerely thank the native English-speaking professional editor for her help in English language.

1 Tang M C, Li C Q. The fact analysis on "the Tibetan Plateau is the startup region of climate change". China Society on the Tibetan Plateau, ed. The Paper Volume of the First Academic Meeting of China Society on the Tibetan Plateau (in Chinese). Beijing: Science Press, 1992. 42-48

2 Feng S, Tang M C, Wang D M. New evidence for the Qinghai-Xizang (Tibet) Plateau as a pilot region of climatic fluctuation in China. Chin Sci Bull, 1998, 43: 1745-1749

3 Liu X D, Luo S W, Qian Y P. Numerical simulations of different thermal characteristics on ground surface of Tibetan Plateau on the over Se-Asia (in Chinese). Plateau Meteorol, 1989, 8: 205-216

4 Wu B Y, Yang K, Zhang R H. Eurasian snow cover variability and its association with summer rainfall in China. Adv Atmos Sci, 2009, 26: 31-44

5 Tang M C, Sun S H, Zhong Q, et al. The energy variation of the underlying surface and the changes of the weather and climate (in Chinese). Plateau Meteorol, 1982, 1: 24-34

6 Xu G C, Li M F. Temperature in Qinghai-Xizang Plateau and the atmospheric circulation in the East Asia (in Chinese). Plateau Meteorol, 1985, 4: 185-189

7 Huang Z S. A preliminary analysis of the correlation between the state of heat and ultra-long wave in the Qinghai-Xizang Plateau (in Chinese). Geogr Res, 1986, 5: 32-41

8 Wang C H, Dong W J, Wei Z G. Study on relationship between the frozen-thaw process in Qinghai-Xizang Plateau and circulation in East-Asia (in Chinese). Chin J Geophys, 2003, 46: 309-316

9 Pavlov A V. Current change of climate and permafrost in the Arctic and sub-arctic Russia. Permafrost Periglac Process, 1994, 5: 101-110

10 Li R, Zhao L, Ding Y J, et al. The climatic characteristics of the maximum seasonal frozen depth in the Tibetan Plateau (in Chinese). J Glaciol Geocryol, 2009, 31: 1050-1056

11 Li S X, Nan Z T, Zhao L. Impact of freezing and thawing on energy exchange between the system and environment (in Chinese). J Glaciol Geocryol, 2002, 24: 109-115 
12 Zhang T J, Stamnes K. Impact of climatic factors on the active layer and permafrost at Barrow. Alaska, 1998, 9: 229-246

13 Ding Y J, Ye B S, Liu S Y, et al. Monitoring of frozen soil hydrology in macro-scale in the Qinghai-Xizang Plateau. Chin Sci Bull, 2000, 45: 1143-1149

14 Zhao L, Cheng G D, Li S X, et al. Thawing and freezing processes of active layer in Wudaoliang region of Tibetan Plateau. Chin Sci Bull, 2000, 45: 2181-2187

15 Wu Q B, Shen Y P, Shi B. Relationship between frozen soil together with its water-heat process and ecological environment in the Tibetan Plateau. J Glaciol Geocryol, 2003, 25: 250-255

16 Ji G L, Yao L C, Yuan F M. Characteristics of surface and atmospheric heating fields over Qinghai-Xizang Plateau during the winter in 1982. Sci China Ser B, 1986, 29: 867-888

17 Li D L, Ji G L, Lu L Z. Impact of Tibetan Plateau surface heating field intensity on Northern hemispherical general circulations and weather and climate of China. Sci China Ser D-Earth Sci, 2001, 44(Suppl): 390-399

18 Zeng Q Z, Xie Y Q. Thermodynamical effects on the Qinghai-Xizang Plateau from the radiation balance and heat balance of the earth's surface. Chin Sci Bull, 1980, 25: 683-688

19 Kou Y G. A study of heat balance at the Earth's surface over Qinghai-Xizang Plateau. Chin Sci Bull, 1980, 25: 343-347

20 Li G P, Duan T Y, Kong Y F. The bulk transfer coefficients and surface fluxes on the western Tibetan Plateau. Chin Sci Bull, 2000, 45: $1221-1226$

21 Cheng G D, Wu T H. Responses of permafrost to climate change and their environmental significance, Qinghai-Tibet Plateau. J Geophys Res, 2007, 112, F02S03

22 Wu Q B, Zhang T J. Changes in active layer thickness over the QTP from 1995 to 2007. J Geophys Res, 2010, 115: D09107

23 Zhao L, Wu Q B, Marchenko S S, et al. Thermal state of permafrost and active layer in Central Asia during the International Polar Year. Permafrost Periglac Process, 2010, 21: 198-207

24 Wu Q B, Zhang T J, Liu Y Z. Permafrost temperatures and thickness on the Qinghai-Tibet Plateau. Glob Planet Change, 2010, 72: 32-38

25 Ge S, Wu Q B, Lu N, et al. Ground water in the Tibetan Plateau, western China. Geophys Res Lett, 2008, 35: L18403

26 Yi S H, Zhou Z Y, Ren S L, et al. Effects of permafrost degradation on alpine grassland in a semi-arid basin on the Qinghai-Tibetan Plateau. Environ Res Lett, 2011, 6: 045403

27 Liu X D, Chen B D. Climate warming in the Tibetan Plateau during the recent decades. Int J Climatol, 2000, 20: 1729-1742

28 Zhao L, Ping C L, Yang D Q, et al. Changes of climate and seasonally frozen ground over the past 30 years in the Qinghai-Xizang (Tibetan) Plateau, China. Glob Planet Change, 2004, 43: 19-31

29 Zhao L, Li R, Ding Y J, et al. Soil thermal regime in Qinghai-Tibet Plateau and its adjacent regions during 1977-2006 (in Chinese). Adv Clim Change Res, 2011, 7: 307-316

30 Zhou Y W, Guo D X, Qiu G Q, et al. Frozen Soil in China (in Chinese). Beijing: Science Press, 2000

31 Romanovsky V E, DDrozdov D S, Oberman N G, et al. Thermal state of permafrost in Russia. Permafrost Periglac Process, 2010, 21: $136-155$

Open Access This article is distributed under the terms of the Creative Commons Attribution License which permits any use, distribution, and reproduction in any medium, provided the original author(s) and source are credited. 